\title{
Shabát Aruká: Un chapuzón a la vida de George Steiner \\ Steiner, G. (2016). Un largo sábado. Conversaciones con Laure Adler (2 edición). Madrid: Ediciones Siruela, 139 pp.
}

\author{
Edwin Mayoral Sánchez ${ }^{1}$ \\ Universidad de Colima (México) \\ edwin_mayoral@ucol.mx
}

Recibida: 25/09/2019 Aprobada: 05/04/2020

DOI: doi.org/10.17533/udea.lyl.n78a20

$\mathrm{E}$ n 2004 Francisco (Patxi) Laca Arocena, uno de mis profesores de psicología, me obsequió Lecciones de los maestros, de George Steiner. ¿Quién demonios era este autor? Lo desconocía y era la primera vez que cargaba entre mis manos una obra steineriana. Consulté en Wikipedia su nombre: crítico literario y cultural judío (conocería más detalles en su autobiografía Errata). Confieso que ese primer encuentro con Steiner fue dilatado y extenuante - mi interés es la psicología social, no husmear en la crítica literaria-. Con el tiempo comprendí que Lecciones de los maestros es uno de los libros más complicados de Steiner (alardea allí de cultura enciclopédica): era el resultado de habitar (de 2001 a 2002) la prestigiosa cátedra Charles Eliot Norton de poesía en la Universidad Harvard; antecedida nada menos que por T. S. Eliot, Robert Frost, Jorge Luis Borges, Octavio Paz y Umberto Eco.

Desde aquella coincidencia, busqué y leí con celo casi todas las obras de Steiner; la mayoría de ellas traducidas y publicadas al español por Ediciones Siruela. Un largo sábado es el libro número 19 de George Steiner que publica Siruela (el primero de ellos fue Pasión intacta, en 1997). En la portada, aparece Steiner sentado con un suéter rojo; apoya su mano izquierda en una mesa y a unos centímetros se ubica su taza. Es la clásica pose en las fotos de Steiner: sonrisa con los labios semiapretados y la ceja derecha levantada con ligereza. El

1. Agradecimientos a los integrantes del curso-taller para escribir con nitidez (Secretaría de Cultura de Colima); agradecimientos especiales para el Prof. Dr. Servando Ortoll, así como a las compañeras Carolina Vázquez Montalvo y Graciela Ceballos de la Mora. 
cuidado de esta segunda edición es escrupuloso, obsesivo: detecté unos pocos gazapos fútiles que se desdibujan con lo atrayente del contenido.

El libro original fue publicado en 2014, en francés, con el título: Un long samedi. Entetiens por ediciones Flammarion; se trata de una serie de entrevistas (de 2002 a 2014) entre Steiner y la periodista francesa Laure Adler, revisadas y reestructuradas por ellos. Adler cuenta en la introducción una anécdota de cómo conoció a George Steiner. En principio, la periodista fue venturosa al entrevistarlo, ya que Steiner odia las entrevistas. O las detestaba... hasta que Laure lo pescó. El 24 de septiembre de 2019 esta reseña fue enviada para su posible publicación a Lingüística y Literatura. George Steiner falleció el 3 de febrero de 2020, a los 90 años. Dados los pormenores biográficos de Un largo sábado - y sin que la intención inicial fuera esa—, esta reseña constituye un merecido y manifiesto obituario.

La prosa de Francis —nombre que nunca usó en público- George Steiner se saborea de a poco: considerado «el mayor crítico literario vivo y el último humanista» — marbete que, por las ideas vertidas en sus textos, aseguro fue risible para él- Harold Bloom quien expiró el 14 de octubre de 2019, a los 89 años-, crítico literario judío, afincado en Estados Unidos, fue calificado otro gigante de la crítica literaria. Prefiero, sin embargo, al laberíntico George sobre Harold; las razones de mi simpatía steineriana las colocaré espero- en el breve paso de esta reseña. Los humanos tememos a la ambigüedad, Steiner nos empuja a capear la falta de certeza en sus resueltas, agoreras y en ocasiones poco diplomáticas ideas. Un largo sábado —o Shabát Aruká en hebreo, para honrar al autor judío - se compone de seis apartados, encarrilados para los lectores convencidos de que la búsqueda intelectual es la flor de sal de la vida.

George Steiner y Laure Adler conversan sobre «El Libro» (la Biblia); de su marca en la historia occidental, y de cómo somos herederos de ese texto milenario. Se remontan a la génesis de la escritura literaria en el Gilgamesh —el gran poema épico de la vieja Babilonia_, o la obra literaria más antigua del mundo. Defensor acérrimo de aprender de memoria, Steiner señaló desde hace décadas lo que hoy las neurociencias pregonan: la 
atención es muscular. -No imagino qué pensó sobre el aprendizaje basado en competencias, lo opuesto al aprendizaje mnemotécnico- Steiner se oponía a las lecturas de fácil digestión; el Reader's Digest es un ejemplo.

El relato de la Torre de Babel sirvió a Steiner para edificar Después de Babel (1975), su libro más ambicioso. La cuestión del multilingüismo y la traducción como apertura a universos alternativos, son dos de los grandes temas que le atrajeron irresistiblemente. Distintas anécdotas corren en el libro. Por ejemplo, de la primera vez que se pronunció en público la palabra esperma, Steiner habla sobre el lenguaje tecnológico, del que se confesó ignorante absoluto. Pero nos interroga: ¿en realidad sabemos cómo funciona el teléfono celular, el Twitter, el Facebook?; «Estamos rodeados de instrumentos sobre los que no comprendemos nada» (p. 57).

Steiner vilipendia a Sigmund Freud y al psicoanálisis. Y no es para menos: si la eficacia de la terapia psicoanalítica es turbia — ¿o absurda?_, su sostén epistemológico lo es aún más. En La poesía del pensamiento (2011), Steiner será contundente: Freud no era un neurólogo o psicólogo; sino un prolijo escritor - Freud fue condecorado en 1930 con el premio Goethe de literatura-. Steiner, uno de los mayores especialistas de Sófocles, estoquea a Freud en uno de sus conceptos torales: «[...] para mí la idea del Edipo viene de una mala lectura de Sófocles. No tiene ningún sentido, es una patraña» (p. 95).

En la mayoría de textos steinerianos giran cuestiones sobre qué nos humaniza o nos deshumaniza; hasta dónde y por qué soportamos las atrocidades y la violencia: «los campos de exterminio, los campos de Stalin y las grandes masacres no han venido del desierto del Gobi; se deben a la alta civilización rusa y europea, se deben al centro mismo de nuestros mayores logros artísticos y filosóficos; y las humanidades no han ofrecido resistencia» (p. 100). Un dechado de esta idea lo encontramos en la crítica moral/ética sobre el nacionalismo alemán de Martin Heidegger. En su magistral Heidegger (1978), Steiner sopesa la compleja biografía del filósofo germano y de qué manera fue un titán de la filosofía y del lenguaje. Steiner odió el nacionalismo y los chauvinismos; fue antisionista. En Israel se le catalogó persona non grata; no obstante, en muchos de sus trabajos reflexionó sobre la excelencia intelectual judía. La respuesta al genio judío se encuentra, 
según él, en la diáspora; por ello se interroga: ¿el peligro es padre de la creación y de la invención?

Detalla Steiner que nació con un defecto físico en el brazo; relata su empleo para The Economist, cubriendo el debate sobre potencias nucleares y la entrevista al físico teórico Robert Oppenheimer. Gracias a una enmarañada historia, Oppenheimer invitó a Steiner al Institute for Advanced Study, en Princeton, como primer joven humanista - recordemos que se conoce ese Instituto por acoger a Albert Einstein-. Allí, Steiner conoció a los físicos y matemáticos de la época: Niels Bohr, John von Neumann, André Weil —hermano de la filósofa Simone Weil-. Conjeturo que, tras esta experiencia en Princeton, George Steiner se obsesionó por lo que él denomina «el pensamiento de primer orden», es decir, los gigantes del intelecto, no solo los de la creación literaria. Muchos de los colegas de Steiner lo desairaron por vituperar a los críticos literarios: desde Tolstói o Dostoievski — su primera publicación en 1959- «no he parado de decir que el creador está a años luz del que comenta o interpreta» (p. 130).

Chascarrillos para loar el tipo de pensamiento al que refiere Steiner son comunes en $U n$ largo sábado: «[Edmund] Husserl es un hombre extraordinario porque era capaz de quedarse sentado, pensando, seis o siete horas seguidas. Es poco frecuente. Encarnaba el pensamiento» (p. 111). La imagen que Steiner evidenció de sí mismo fue la de un ser alejado de lo terrenal, dedicado solo al intelecto; racionalizando cada acto cotidiano. Lo contemplamos, por ejemplo, cuando se arrepintió de no probar el LSD cuando tuvo la oportunidad. Yo no he consumido LSD, pero bebí ayahuasca en 2015; coincido con Steiner en que la entrada a los entéogenos es una experiencia cuyo bagaje es difícil trasmitir.

El profesor Steiner reconoció su misión como la del cartero (Il Postino; son sus palabras) de los próceres de la literatura, la poesía y la filosofía. En un apartado de Un largo sábado narra la anécdota de ser pionero en popularizar al poeta Paul Celan. Si Steiner se autopercibió como un mensajero de las bellas letras, destacó en su labor: en la Universidad de Ginebra encabezó la cátedra de literatura comparada más antigua, bautizada con exquisitez como Littérature générale. No solo George Steiner sobresalió en su profesión: su hija Deborah Steiner es profesora de griego y latín clásico en la Universidad de Columbia en la Ciudad de Nueva York. 
Desfila por este libro una multiplicidad temática que rozó George Steiner: el temor al óbito; el apoyo a la eutanasia y el aborto; el ateísmo; su postura política; sus inclinaciones musicales — «Un día sin música es un día muy triste», (p. 105) —; el trasfondo religioso en el arte; las particularidades que calculó sine qua non para leer; el afecto a los perros. El valor de Un largo sábado radica en que es una incursión en el pensamiento de Steiner; durante este itinerario se ojea su historia, distinta a la de su autobiografía Errata. Como muestra, me enteré de que Steiner asistió a clases con el etnólogo Claude Lévi-Strauss; que conoció al líder sionista David Ben-Gurión, así como a los filósofos Hannah Arendt y Hans-Georg Gadamer. Además, supe que, aunque surgió la ocasión, esquivó toparse con Heidegger.

Un largo sábado es, sin duda, un libro recomendable. Pero no es un texto dulce, ni políticamente correcto; por momentos nos dejará fuera de combate. Tal y como mencionó Franz Kafka en una carta de 1904 al historiador del arte checo Oskar Pollak: «Un libro debe ser el hacha que quiebra el mar helado que tenemos dentro». 